\title{
Reinstatement in honeybees is context-dependent
}

\author{
Jenny Aino Plath, ${ }^{1}$ Johannes Felsenberg, ${ }^{1}$ and Dorothea Eisenhardt ${ }^{2}$ \\ Freie Universität Berlin, FB Biologie, Pharmazie, Chemie, Institut für Biologie, Neurobiologie, Königin-Luise-Strasse \\ 28/30, 14195 Berlin, Germany
}

\begin{abstract}
During extinction animals experience that the previously learned association between a conditioned stimulus (CS) and an unconditioned stimulus (US) no longer holds true. Accordingly, the conditioned response (CR) to the CS decreases. This decrease of the CR can be reversed by presentation of the US alone following extinction, a phenomenon termed reinstatement. Reinstatement and two additional phenomena, spontaneous recovery and renewal, indicate that the original CS-US association is not lost through extinction but can be reactivated through different processes. In honeybees (Apis mellifera), spontaneous recovery, i.e., the time-dependent return of the $C R$, has been demonstrated, suggesting that also in these insects the original CS-US association is not lost during extinction. To support this notion, we ask whether honeybees show reinstatement after extinction. In vertebrates reinstatement is context-dependent, so we examined whether the same holds true for honeybees. We demonstrate reinstatement in restrained honeybees and show that reinstatement is context-dependent. Furthermore, we show that an alteration of the color of light illuminating the experimental setup suffices to indicate a contextual change. We conclude that in honeybees the initially formed CS-US memory is not lost after extinction. Rather, honeybees might learn about the context during extinction. This enables them to adequately retrieve one of the two opposing memories about the CS that have been formed after extinction.
\end{abstract}

In classical conditioning an animal learns to associate an initially meaningless conditioned stimulus (CS) with an unconditioned stimulus (US). After a CS-US association has been formed the animal responds with a conditioned response (CR) to the CS alone. Further CS presentations without a subsequent US lead to a reduction of responses to the CS, which is termed extinction (e.g., Myers and Davis 2002). During extinction the animal learns that the CS is no longer associated with the US.

The current view is that extinction learning does not destroy the original CS-US association (Bouton 2004). Rather, a new CSnoUS association is learned, leaving the original CS-US association intact (Bouton 2004). This view is based on the observation of three behavioral phenomena in conjunction with extinction. The occurrence of these phenomena, namely, spontaneous recovery, renewal, and reinstatement, reveals a time- or context-dependent reappearance of the CR after extinction (Myers and Davis 2002), indicating that the original CS-US association is not lost during extinction but can be reactivated through different processes (Bouton 2004). Accordingly, after extinction two memories about the association of the CS with the US are formed, i.e., a CSUS memory and a CS-noUS memory, resulting in an "ambiguous meaning of the CS" (Bouton et al. 2006). It is still rather unclear how these two memories are organized and under which circumstances each memory can be retrieved.

In the honeybee (Apis mellifera), an invertebrate model of learning and memory, spontaneous recovery has been described as an extinction-related phenomenon (Sandoz and Pham-Delegue 2004; Stollhoff et al. 2005). This finding supports the idea that also in honeybees the original CS-US association is not lost through extinction, but reappears over time. The occurrence of renewal and reinstatement would support this notion, but neither of these phenomena has been described in the honeybee so far. Therefore, in this study we aim to demonstrate reinstatement

\footnotetext{
1These authors contributed equally to this work.

${ }^{2}$ Corresponding author

E-mail dorothea.eisenhardt@fu-berlin.de

Article is online at http://www.learnmem.org/cgi/doi/10.1101/Im.026831.112.
}

in honeybees. Because it is known that the context plays a key role in reinstatement (Bouton and Bolles 1979; Westbrook et al. 2002), we focus on the question of whether reinstatement in honeybees is context-dependent.

Extinction learning and its underlying mechanisms are studied in honeybees in a classical appetitive conditioning paradigm, the olfactory conditioning of the proboscis extension response (PER) (Takeda 1961; Bitterman et al. 1983; Giurfa and Sandoz 2012). In this paradigm extinction is well characterized: After pairing an odor (CS) with a sucrose reward (US) honeybees learn the association between the CS and the US and form a memory about this association (Bitterman et al. 1983; Felsenberg et al. 2011). Presentation of at least two CS trials alone on the day after conditioning leads to extinction learning and the formation of a consolidated extinction memory $1 \mathrm{~d}$ later (Stollhoff et al. 2005; Stollhoff and Eisenhardt 2009).

Here we demonstrate that reinstatement does indeed occur in honeybees and that, comparable to vertebrates, it is contextdependent. Furthermore, we show that the color of light serves as a learning context in honeybees. We discuss these findings in the framework of honeybee foraging behavior.

\section{Results}

\section{Reinstatement in honeybees}

Reinstatement is defined as the reappearance of the extinguished CR due to a presentation of the US between extinction and the retention test (Bouton 2004). The first experiment was designed to investigate whether a reinstatement effect could be demonstrated in honeybees, i.e., whether the decrease of the CR induced by extinction training can be reversed by a US presentation.

The experiment was designed such that acquisition, extinction, reinstatement, and the retention test were performed within a 6 -h period. Acquisition consisted of one trial for all bees. Three hours later the bees were divided into two groups. The first group was subjected to extinction (E), while the second group was left undisturbed in the storage box and remained nonextinguished 
A

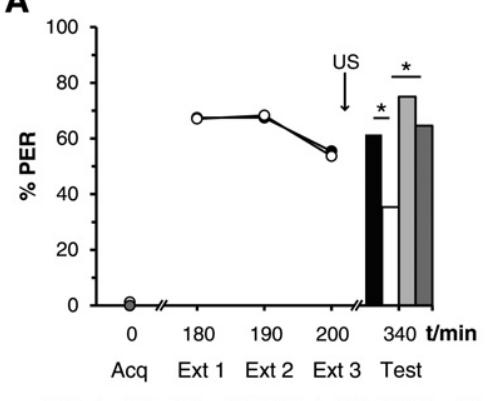

- $E+(n=83) \square E-(n=82) \square N E+(n=84) \square N E-(n=83)$

B

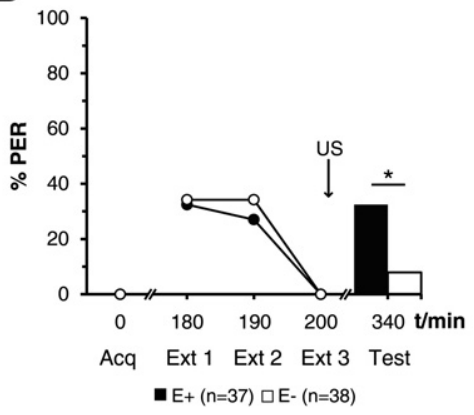

Figure 1. US presentation after extinction reinstates the CR. (A) All bees were trained with one acquisition trial (Acq). Three hours later, the groups $\mathrm{E}+$ and $\mathrm{E}-$ received three extinction trials (Ext 1 -Ext 3; ITI, 10 min), whereas the groups $\mathrm{NE}+$ and $\mathrm{NE}$ - did not receive any extinction trial. In $\mathrm{E}+$ and $\mathrm{E}-$, extinction over the three trials was significant $(P<$ $0.05)$. Ten minutes after extinction, $\mathrm{E}+$ and $\mathrm{NE}+$ received one US presentation alone (indicated with an arrow), whereas NE - and $\mathrm{E}$ - were left untreated. Memory retention of all four subgroups was tested in the final memory test (Test). A significant difference between $\mathrm{E}+$ and $\mathrm{E}-$ was found $(P<0.01)$, indicating successful reinstatement. (B) Animals of the extinguished subgroups $(E+, E-)$ which did not exhibit a $C R$ at the last extinction trial were selected. In the final memory test the retention scores between these selected animals of both subgroups were significantly different. This difference indicates the proportion of reestablished $\mathrm{CR}$ that is caused by the US presentation in group $\mathrm{E}+$ (absolute reinstatement) $(P<0.05)$. $\left({ }^{*}\right)$ Significant differences; $(E)$ extinguished; (NE) nonextinguished; (+) US-only trial; $(-)$ no US-only trial.

(NE). During extinction the animals received three CS presentations alone with an intertrial interval (ITI) of $10 \mathrm{~min}$. After extinction the two groups (E and NE) were divided into four subgroups, two receiving a US presentation $(\mathrm{E}+$ and $\mathrm{NE}+) 10$ min after the last extinction trial and two that were left undisturbed $(\mathrm{E}-$ and $\mathrm{NE}-$ ). For all four subgroups $(\mathrm{E}+, \mathrm{E}-, \mathrm{NE}+$, and $\mathrm{NE}-$ ) a final memory test was conducted $2 \mathrm{~h}, 10 \mathrm{~min}$ later.

In both extinguished subgroups $(\mathrm{E}+, \mathrm{E}-)$ within-session extinction between the first and third trial was statistically significant (McNemar; $\chi_{\mathrm{E}+}^{2}=5.79 ; P<0.05$ and $\chi_{\mathrm{E}-}^{2}=6.67 ; P<0.05$ $\mathrm{df}=1$ ) (Fig. 1A). In the extinguished subgroup receiving a subsequent US presentation (E+), 26\% more bees responded in the final memory test than in the group that did not receive this US presentation (E-). This difference was statistically significant (G-test; $\mathrm{G}_{\mathrm{E}+\text { vs. } \mathrm{E}-}=11.36 ; P<0.01 ; \mathrm{df}=1$ ). No significant difference was observed between retention scores of the two nonextinguished subgroups (NE+ and $\mathrm{NE}-$ ) even though one of these groups received a US presentation $(\mathrm{NE}+)$ and one did not $(\mathrm{NE}-)$ $\left(\mathrm{G}_{\mathrm{NE}+}\right.$ vs. $\left.\mathrm{NE}-=2.21 ; P>0.01 ; \mathrm{df}=1\right)$. These findings demonstrate that the delivery of the US following extinction reverses extinction, i.e., the decrease of the CR.

Furthermore, retention scores at the final memory test differed between the extinguished subgroup E- and the nonextin- guished subgroup $\mathrm{NE}-\left(\mathrm{G}\right.$-test; $\mathrm{G}_{\mathrm{E}-\text { vs. } \mathrm{NE}-}=14.26 ; P<0.01$; $\mathrm{df}=1$ ), indicating effective extinction after three trials. No difference was observed between the extinguished subgroup receiving a US-only trial $(\mathrm{E}+)$ and the nonextinguished subgroups $(\mathrm{NE}+$ or $\mathrm{NE}-)\left(\mathrm{G}\right.$-test; $\mathrm{G}_{\mathrm{NE}+\text { vs. } \mathrm{E}+}=3.56 ; P>0.01 ; \mathrm{df}=1 ; \mathrm{G}$-test; $\mathrm{G}_{\mathrm{NE}-\mathrm{vs} \text {. }}$ $\mathrm{E}+=0.18 ; P>0.01 ; \mathrm{df}=1)$. This demonstrates that the US presentation following extinction reinstates the retention scores to the level of animals that were not extinguished.

In a further analysis, only animals that did not respond in the third extinction trial were selected (Fig. 1B). In the final memory test the proportion of animals from the extinguished subgroup $\mathrm{E}+$ was determined, in which the $\mathrm{CR}$ was reestablished due to a presentation of the US after extinction. We termed this reestablishment of the CR "absolute reinstatement" (based on the term "absolute recovery") established by Sandoz and Pham-Delegue (2004). In the retention test significantly more animals reestablished the $\mathrm{CR}$ in $\mathrm{E}+$ compared with $\mathrm{E}-\left(\mathrm{G}\right.$-test; $\mathrm{G}_{\mathrm{E}+\text { vs. } \mathrm{E}-\mathrm{=}}$ 7.44; $P<0.05 ; \mathrm{df}=1)$.

Accordingly, the increase of CR observed in the first analysis was not merely caused by animals, which still responded at the third extinction trial and continued to respond at the final memory test, but also by animals showing absolute reinstatement.

In summary, this experiment revealed that one US trial alone presented after extinction induces reinstatement of the CR.

\section{Reinstatement is not due to sensitization}

Next we wanted to exclude that sensitization caused the reinstatement phenomenon observed above. Sensitization is defined as the increase of a behavioral response to a stimulus after the presentation of a strong meaningful stimulus (Thompson and Spencer 1966; Castellucci et al. 1970), in this case the reward. We asked to what extent the US, i.e., the stimulation with sucrose, enhances the response to a subsequently presented odor. Two groups were run in parallel: One group was exposed to one US alone (US), the second group was left untreated and remained in the storage box (NT). The response to an odor was tested $2 \mathrm{~h}, 10 \mathrm{~min}$ after US delivery in both groups.

The responses to the odor of the naive group and the US-stimulated group were not significantly different (G-test; $\mathrm{G}_{U S}$ vs. NT $=2.51 ; P>0.05 ; \mathrm{df}=1$ ) (Fig. 2 ). We therefore conclude that the US presentation in itself does not account for the increase of CR after the presentation of a US following extinction.

\section{Reinstatement is context-dependent}

In vertebrates reinstatement of an extinguished memory has been shown to be context-dependent (Bouton and Bolles 1979). We

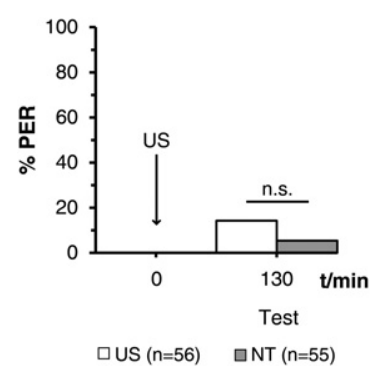

Figure 2. Reinstatement is not due to sensitization. At the beginning of the experiment, one US was presented to half of the bees (US) and the second half of the animals remained untreated (NT). Two hours and $10 \mathrm{~min}$ later, the response of both groups to odor presentation was tested (Test). No significant difference between the response scores of both groups was found. Thus, sensitization was not observed $2 \mathrm{~h}, 10 \mathrm{~min}$ after US presentation ( $P>0.05)$. (Arrow) Time point of US stimulation. 


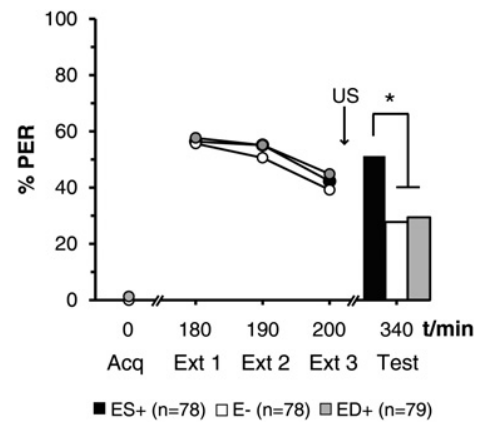

Figure 3. Context dependency of reinstatement. All groups received one acquisition trial (Acq) and three extinction trials (Ext 1-Ext 3). In all groups, the percentage of responding animals decreased significantly over these three trials $(P<0.05)$. One group subsequently received one US presentation alone (arrow) in the same experimental setup (ES+). Another group was transferred into a gray plastic box (different context) and received the US presentation in this box $(E D+)$. The third group did not receive a US presentation following extinction $(E-)$. In the final memory test (Test), significantly more bees of the ES + group responded to the CS compared with the ED + and the $\mathrm{E}-$ groups $(P<0.017) .\left(^{*}\right)$ Significant differences; (E) extinguished; (S) same context; (D) different context; (+) US-only trial; $(-)$ no US-only trial.

next tested whether reinstatement occurs in honeybees when the US presentation is conducted in a context that is different from the context encountered during acquisition and extinction. The overall design was based on the first experiment.

All bees received one acquisition trial and $3 \mathrm{~h}$ later three extinction trials (ITI , $10 \mathrm{~min}$ ) in the experimental setup. Ten minutes after the last extinction trial, one group of bees received the US presentation alone in the same context, i.e., the experimental setup where acquisition and extinction took place (ES+). Another group of bees was transferred to a different context, i.e., a gray plastic box, where they received the US presentation (ED+). A third group remained untreated after the extinction $(\mathrm{E}-)$. All three groups were tested $2 \mathrm{~h}, 10 \mathrm{~min}$ later in the experimental setup where acquisition and extinction took place.

In all groups, the responses significantly decreased during extinction $\left(\right.$ McNemar; $\chi_{\mathrm{ES}+}^{2}=5.26 ; P<0.05, \chi_{\mathrm{E}-}^{2}=7.58 ; P<0.05$, $\chi_{\mathrm{ED}+}^{2}=4.05 ; P<0.05, \mathrm{df}=1$ ) (Fig. 3). The response scores in the final memory test did not differ significantly between the group that did not receive a US presentation $(\mathrm{E}-)$ and the group that received the US presentation in a different context (ED+) (G-test; $\mathrm{G}_{\mathrm{E}-}$ vs. $\left.\mathrm{ED}+=0.05 ; P>0.017 ; \mathrm{df}=1\right)$. The response scores of bees that received a US presentation in the context of acquisition and extinction (ES+) were significantly higher compared with the $\mathrm{ED}+$ group and the $\mathrm{E}-$ group (G-test; $\mathrm{G}_{\mathrm{ES}+\text { vs. } \mathrm{E}-=9.12 ; P<}$ $\left.0.017, \mathrm{G}_{\mathrm{ES}+\text { vs. } \mathrm{ED}+}=7.77 ; P<0.017, \mathrm{df}=1\right)$.

Taken together, only a US presentation in the same context as during acquisition and extinction induced reinstatement of the CR in the retention test. This finding supports the idea that reinstatement is context-dependent.

\section{Light as part of the context in reinstatement}

In the previous experiment we changed the context by transferring the animals to a gray box, hypothesizing that animals placed in this gray box perceived a different color compared with the experimental setup. Therefore, we next tested whether the color of light illuminating the experimental setup is sufficient to signal a contextual change.

We used light with wavelengths from two sides of the spectrum, specifically lights that appear blue and yellow to humans. In acquisition and extinction (three trials; ITI, $10 \mathrm{~min}$ ), either the blue (B) or the yellow light (Y) was switched on throughout the trials. After extinction, the blue group and the yellow group were further divided into three subgroups each: One subgroup received the US in the same light (BS+ or YS+), one subgroup received the US in the different light $(\mathrm{BD}+$ or $\mathrm{YD}+)$, whereas the remaining subgroup was left untreated $(\mathrm{B}-$ or $\mathrm{Y}-$ ). Memory retention of all six subgroups was tested in the same light present during acquisition and extinction $2 \mathrm{~h}, 10 \mathrm{~min}$ after the extinction session.

No significant differences between the CRs of the extinction trials in yellow light or in blue light were observed (repeatedmeasurement ANOVA; $F_{(1,221)}=0.82 ; P>0.05$ ) (Fig. 4A). Thus, extinction was not modified by the color of light present during acquisition and extinction.
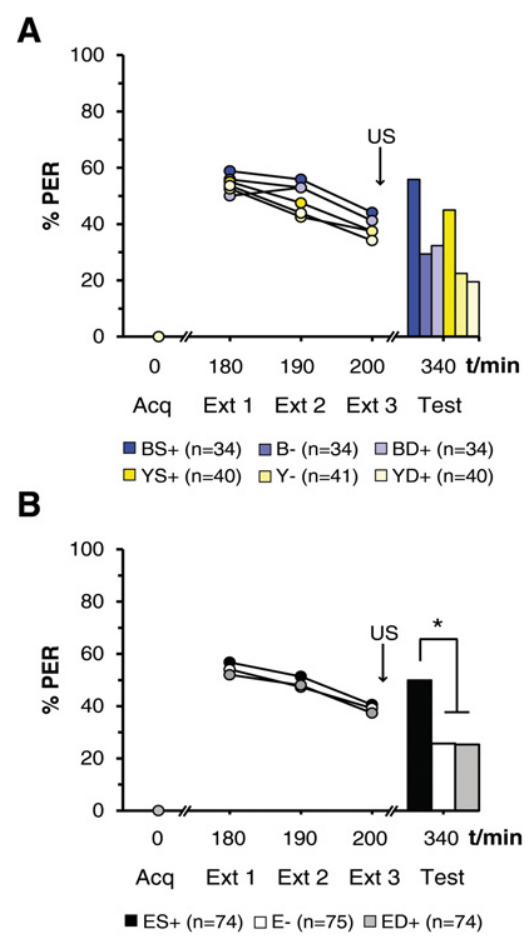

Figure 4. Light as part of the context in reinstatement. $(A)$ Bees received one acquisition trial (Acq) and three extinction trials (10-min ITI; Ext1Ext3) in the experimental setup illuminated with either blue or yellow light. No significant differences were found between extinction scores in blue and in yellow light $(P>0.05)$. After extinction, bees treated in one color were further divided into three subgroups. Two subgroups received a US presentation alone (arrow) in the same light (BS+ and YS+) presented during acquisition and extinction. Two subgroups received the US presentation in the color they had not encountered before $(B D+$ and $Y D+)$. The remaining subgroups did not receive any US presentation at all ( $B-$ and $Y-)$. The $C R$ was tested in a final memory test (Test) during which the setup was again illuminated with the colored light already encountered during acquisition and extinction. The retention scores of animals that were trained and extinguished in either blue light or in yellow light were not significantly different from each other in the respective groups (BS+ and $\mathrm{YS}+, \mathrm{BD}+$ and $\mathrm{YD}+, \mathrm{B}-$ and $Y-)(P>0.05)$. (B) Results for the pooled groups $E S+(B S+$ and $\mathrm{YS}+), \mathrm{ED}+(\mathrm{YS}+$ and $\mathrm{BS}+)$, and $\mathrm{E}-(\mathrm{B}-$ and $\mathrm{Y}-)$ : In all three groups, the CR decreased significantly over three extinction trials $(P<0.05)$. The $C R$ was tested in a final memory test (Test) during which the setup was again illuminated with the light encountered during acquisition and extinction. In the final memory test, CR was significantly different for $\mathrm{ES}+$ compared with $\mathrm{ED}+$ and $\mathrm{E}-\left(P^{\prime}<0.025\right) .\left(^{*}\right)$ Significant differences; (B) blue light; $(Y)$ yellow light; $(E)$ extinguished; $(S)$ same light; (D) different light; $(+)$ US-only trial; ( - no US-only trial. 
Retention scores at the final memory test were not significantly different between each of the two subgroups experiencing either blue or yellow during acquisition and extinction and the subsequent US presentation in the same color (BS+ and YS+), in the different color $(\mathrm{BD}+$ and $\mathrm{YD}+)$, or no subsequent US presentation at all $(\mathrm{B}-$ and $\mathrm{Y}-)\left(\mathrm{G}\right.$-test; $\mathrm{G}_{\mathrm{BS}+}$ vs. $\mathrm{YS}+=0.87 ; P>$ $0.05, \mathrm{G}_{\mathrm{BD}+\text { vs. } \mathrm{YD}+}=1.62 ; P>0.05, \mathrm{G}_{\mathrm{B}-\text { vs. } \mathrm{Y}-}=0.46 ; P>0.05$, $\mathrm{df}=1)$. Therefore, the two respective groups $(\mathrm{BS}+$ and $\mathrm{YS}+$, $\mathrm{BD}+$ and $\mathrm{YD}+, \mathrm{B}-$ and $\mathrm{Y}-$ ) were pooled for further analysis, resulting in three groups: ES+ (US presentation in the same light), $\mathrm{ED}+$ (US presentation in different light), and $\mathrm{E}-$ (no US presentation) (Fig. 4B). In all three groups the CR decreased significantly over the three trials (McNemar; $\chi_{\mathrm{ES}+}^{2}=8.64 ; P<0.05, \chi_{\mathrm{ED}+}^{2}=$ 6.67; $\left.P<0.05 \chi_{\mathrm{E}-}^{2}=5.88 ; P<0.05, \mathrm{df}=1\right)$. In the retention test animals from the ES+ group responded significantly more than those from the $\mathrm{ED}+$ group and the $\mathrm{E}-$ group (G-test; $\mathrm{G}_{\mathrm{ES}+}$ vs.

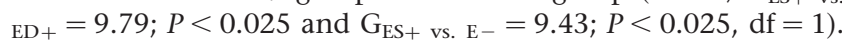
Thus, a US presentation in light that differed from the light presented during acquisition, extinction, and the final memory test, did not result in reinstatement of the CR. This result supports the hypothesis that the color of light illuminating the experimental setup is part of the context in reinstatement.

\section{Light exposure alone does not reinstate the $\mathrm{CR}$}

Next we asked whether an exposure to the light alone without a US would in itself lead to the higher proportion of responses in the final memory test. To address this question the previous experiment was repeated, the only difference being that following extinction the animals were placed into the light without presenting the US. As in the previous experiment, the animals were either placed in the same or in a different light compared with acquisition and extinction.

Again, lights of different wavelengths illuminating the experimental setup were used. Acquisition and extinction were conducted in either blue (B) or yellow (Y) light. All animals were subjected to one acquisition trial and three extinction trials with an ITI of $10 \mathrm{~min}$. Afterward, the animals from the blue group and the yellow group were divided into three subgroups each: One subgroup was placed under the same light for one trial $10 \mathrm{~min}$ after extinction (BSL or YSL), a second subgroup was placed under a different light (BDL or YDL), while the remaining subgroup (Bor $\mathrm{Y}-$ ) was not taken out of the storage box.

The extinction trials of the groups extinguished in yellow or blue light were not significantly different (repeated-measurement ANOVA; $\left.F_{(1,208)}=0.67 ; P>0.05\right)$ (Fig. $5 \mathrm{~A}$ ). The retention scores in the final memory test did not differ significantly between the two groups that were put into the same light (BSL and YSL), a different light (BDL and YDL), or that were not taken out of their storage box $\left(\mathrm{B}-\right.$ and $\mathrm{Y}-$ ) $\left(\mathrm{G}\right.$-test; $\mathrm{G}_{\mathrm{BSL}}$ vs. YSL $=0.01 ; P>0.05 \mathrm{G}_{\mathrm{B}-\text { vs. }}$ $\mathrm{Y}-=1.68 ; \quad P>0.05, \quad \mathrm{G}_{\mathrm{BDL}} \quad$ vs. $\left.\mathrm{YDL}=1.33 ; \quad P>0.05, \quad \mathrm{df}=1\right)$. Therefore, the two respective groups (BSL and YSL, BDL and $\mathrm{YDL}$, and $\mathrm{B}-$ and $\mathrm{Y}-$ ) were pooled for further analysis, resulting in three groups: ESL (extinction, exposure to same light), EDL (extinction, exposure to different light), and $\mathrm{E}-$ (extinction, no exposure to light) (Fig. 5B). A significant within-session extinction was revealed in all three groups $\left(\right.$ McNemar; $\chi_{\mathrm{ESL}}^{2}=13.14 ; P<$ $0.05, \chi_{\mathrm{EDL}}^{2}=13.14 ; P<0.05$ and $\left.\chi_{\mathrm{E}-}^{2}=13.47 ; P<0.05, \mathrm{df}=1\right)$. No differences in CR due to different treatment were observed in the final memory test (G-test; $\mathrm{G}_{\mathrm{ESL}}$ vs. $\mathrm{EDL}=0.13 ; P>0.017$, $\mathrm{G}_{\mathrm{ESL}}$ vs. $\left.\mathrm{E}-=0.30 ; P>0.017 ; \mathrm{G}_{\mathrm{EDL} \text { vs. } \mathrm{E}-}=0.03 ; P>0.017 ; \mathrm{df}=1\right)$.

Taken together, a mere exposure to the light experienced during acquisition, extinction, and the subsequent retention test did not reinstate the CR. Hence, it is the US presentation under a certain light, rather than the exposure to the light alone, that is critical for reinstatement in honeybees. To summarize, we dem-
A

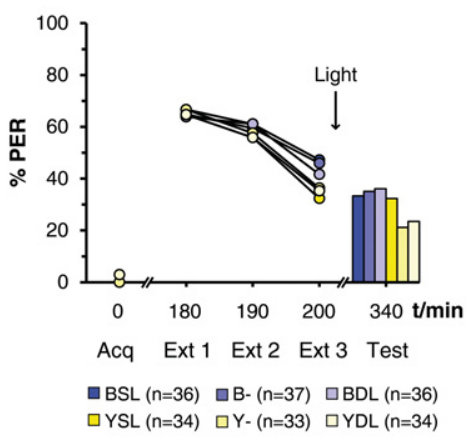

B

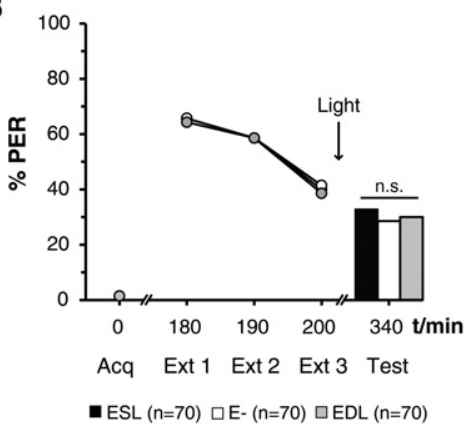

Figure 5. Exposure to light alone does not lead to reinstatement. $(A)$ Bees received one acquisition trial (Acq) and three extinction trials (10-min ITI; Ext1-Ext3) in the experimental setup illuminated with either blue or yellow light. No significant differences were found between extinction scores in blue and in yellow light $(P>0.05)$. Following extinction, bees treated in one color were further divided into three subgroups. Two subgroups were placed into the same light as during acquisition and extinction for $30 \mathrm{sec}$ (BSL and YSL). Two subgroups were placed into a different light for $30 \mathrm{sec}$ (BDL and YDL). The remaining two subgroups were left untreated $(B-$ and $Y-)$. In the final memory test (Test), no differences between retention scores were observed between the respective subgroups for the two colors (BSL and YSL, BDL and YDL, $B-$ and $Y-)(P>0.05)$. (B) Results for the pooled groups ESL (BSL and $Y S L), E D L$ ( $B D L$ and $Y D L)$, and $E-(B-$ and $Y-)$ : All groups showed a significant decrease of $C R$ over three extinction trials $(P<0.05)$. In the final memory test, no differences were detected due to the preceding treatment $(P>0.017)$. (B) Blue light; $(Y)$ yellow light; (S) same light; (D) different light; (L) light exposure trial; (-) no-light exposure trial; (n.s.) not significant.

onstrated that the color of light is a critical part of the context sufficing to signal a contextual change in reinstatement but does not cause reinstatement in itself.

\section{Discussion}

\section{Context-dependent reinstatement in the honeybee}

In this study we have demonstrated reinstatement in honeybees. We have shown that the application of one US-only trial presented 10 min after extinction learning leads to the return of the CR when the previously extinguished CS is presented. Furthermore, we have shown that reinstatement is context-dependent: The return of the CR can only be observed when the US-only trial is presented in the context of acquisition and extinction learning. No return of the CR is observed when the US is presented in a different context or when the context is presented alone. Furthermore, we demonstrated that honeybees are able to distinguish a context when the only variable is the light illuminating the experimental setup. We conclude that honeybees perceive this visual stimulation and relate the information to previous experiences. This 
finding could appear surprising because appetitive conditioning of visual stimuli in harnessed honeybees has proven to be rather difficult and only to some extent possible if the antennae were ablated (Kuwabara 1957; Hori et al. 2006, 2007; Niggebrügge et al. 2009). However, Mota et al. (2011) demonstrated that lights of different wavelengths can be perceived by the honeybee as an occasion-setter, predicting a CS-US or CS-noUS relation although these visual stimuli do not directly trigger a PER. Therefore, Mota et al. (2011) concluded that in honeybees, colors serve as occasion-setters for appropriate odor responding.

Interestingly, the context is also discussed as an occasionsetter in regard to extinction. It has been proposed that the context sets the occasion for the retrieval of a CS-noUS association, i.e., for retrieval of an extinction memory (Bouton and Swartzentruber 1986; Bouton 1993, 2004). This occasion-setting function of the context might be removed by the presentation of the US alone subsequent to extinction, resulting in reinstatement of the response to the previously extinguished CS (Westbrook et al. 2002).

Nevertheless, it should be noted that an occasion-setting function of the context acquired during extinction is only one of the hypotheses regarding the context's role in extinction and reinstatement. Rescorla (1979) proposed that extinction increases the threshold for the CR because the extinction-associated context becomes inhibitory (Rescorla and Cunningham 1977; Rescorla 1979). During reinstatement, the US presentation in the same context might weaken this inhibition and reestablishes a response to the extinguished CS (Westbrook et al. 2002). Additionally, Westbrook et al. (2002) discussed that the context might serve as a link between the CS and the US. He suggested that the context has already been associated with the CS during extinction. This association of the context with the US leads to a reassociation of the CS with the US when it is presented during reinstatement (Westbrook et al. 2002).

Accordingly, although it has long been known that reinstatement is context-dependent (i.e., Bouton and Bolles 1979; Westbrook et al. 2002), the precise mechanism underlying the context dependency of reinstatement still remains to be clarified, not only in honeybees but also in vertebrates.

Reinstatement and the adaptation to varying food sources Our findings of reinstatement together with previous findings of spontaneous recovery in honeybees (Bitterman et al. 1983; Sandoz and Pham-Delegue 2004; Stollhoff et al. 2005) support the notion that in honeybees the original CS-US association is not lost through extinction. Rather, a second CS-noUS trace is formed during extinction learning that suppresses the expression of the original memory.

In the honeybee, the formation of these two opposing memories might play a role in foraging, when bees have to adapt their behavior toward variable food sources (Eisenhardt 2012). Honeybees shift toward a different nectar source when they experience the decline or even failure of the nectar source currently visited (Greggers and Menzel 1993; Greggers and Mauelshagen 1997). This resembles extinction learning and the formation of an extinction memory. Also, however, flowers that provided nectar before but are no longer doing so might still constitute an important, although highly variable, nectar source. Therefore, a memory about the previously experienced association between the flower stimuli, e.g., their odor, and the nectar puts the bee in a position to again search for nectar at these flowers. But as long as this memory is suppressed by the extinction memory, the bee might not again approach the respective food source. A signal that the food source is again providing nectar might be the experience of nectar in the extinction context. This might re- instate the initially learned association and leads to renewed foraging at the previously extinguished food source.

In harnessed honeybees we have demonstrated that the color of light illuminating the experimental setup suffices to indicate a contextual change relevant in reinstatement. In free-flying honeybees the equivalent of light illuminating the experimental setup might be the color of the natural sky light (Pauers et al. 2012) or the color of a flower currently visited by the bee. Hence, both might be components of the context playing a crucial role in reinstatement of free flying honeybees.

Taken together, we propose that in free flying honeybees reinstatement could be a mechanism that regulates an animal's behavior toward a constantly changing environment by ensuring the retrieval of a memory that is relevant in the animal's current situation.

\section{Evolutionary conservation of extinction}

Extinction is discussed in conjunction with possible treatments for disorders such as anxiety disorders, post-traumatic stress responses, and drug addiction (e.g., Schiller et al. 2008; Peters et al. 2009; Holmes and Quirk 2010; Quirk et al. 2010; Duka et al. 2011; Kaplan et al. 2011). Therefore, an understanding of the mechanisms of memory formation and retrieval is particularly important. Accordingly, the mechanisms of extinction are to date predominantly studied in vertebrate model systems, such as mice and rats, or in humans (Graham and Milad 2011). However, besides the honeybee, extinction has also been described in several invertebrate species, such as the crab Chasmagnathus (Tomsic et al. 1998), the crayfish Orconectes rusticus (Nathaniel et al. 2009), the pond snail Lymnea stagnalis (Sangha et al. 2002), and the fruit fly Drosophila melanogaster (Lagasse et al. 2009; Qin and Dubnau 2010). Interestingly, reinstatement and spontaneous recovery have also been demonstrated in several invertebrate organisms, i.e., Orconectes rusticus, Lymnea stagnalis, Chasmagnathus, and Apis mellifera (Sangha et al. 2003; Sandoz and Pham-Delegue 2004; Stollhoff et al. 2005; Carter et al. 2006; Merlo and Romano 2008; Nathaniel et al. 2009; Hepp et al. 2010). These findings suggest that extinction learning and the formation of two opposing memories about the same stimulus are evolutionarily very old mechanisms. Because of its evolutionary conservation, the ability for extinction learning and the formation of extinction memories is crucial for the survival of animals, guaranteeing flexible behavior toward ongoing environmental changes.

Interestingly, although the ability for extinction learning seems to be evolutionarily conserved in both vertebrates and invertebrates, their respective brain architectures are fundamentally different. This suggests that the ability for extinction learning is not rooted in the specific brain architecture but might be a general feature of the nervous systems. A comparative approach to understanding the common mechanism underlying extinction learning in both vertebrates and invertebrates might therefore be a key to solving the question of how two memory traces about an opposing meaning of the CS formed after extinction learning interacts during memory retrieval.

\section{Materials and Methods}

\section{Animals}

For all experiments, honeybees were caught when leaving hives located near the laboratory buildings of the Institute of Neurobiology, Freie Universität Berlin. All animals were immobilized on ice and harnessed in plastic tubes. Afterward, all bees were fed with $4 \mu \mathrm{L}$ of $30 \%$ sucrose solution.

Seventeen hours and $40 \mathrm{~min} \pm 10 \mathrm{~min}$ before the beginning of the experiment, the bees were fed ad libitum with $30 \%$ sucrose 
solution. Overnight and between the single parts of one experiment, the bees were kept in a dark, humid storage box. (Felsenberg et al. 2011).

\section{Odor stimulation}

An olfactometer was used in all experiments. Two constant airstreams were provided by an aquarium pump (seliger $\mathrm{GmbH}$ ) and regulated by flow tube meters (Aalborg Instruments and Controls, Inc.). The main airstream was set to $2 \mathrm{~L}$ per min and led into a metal tip via Teflon and silicon tubes (CARL ROTH GmbH \& Co. KG; Supelco, Sigma-Aldrich). The second odordelivering airstream was set to $240 \mathrm{~mL}$ per min and regulated by a three-way valve (The Lee Company). Via the valve, the airstream could be directed through an odor-containing syringe or an empty syringe. The odorized or odorless airstream was thereby added to the main airstream directed to the bee. The valve was connected to a computer (relay board and an AC/DC converter box, both: $\mathrm{BMC}$ Messsysteme $\mathrm{GmbH}$ ). Odor delivery was timed with a script (by Tilman Franke, modified) written in AutoHotKey (Free Software Foundation, Inc.).

Every day the odor syringe was loaded with $4 \mu \mathrm{L}$ of clove oil (Bombastus-Werke AG) on a round filter paper of $1 \mathrm{~cm}$ in diameter (MACHERY-NAGEL GmbH \& Co. KG). An exhaust located behind the bee immediately removed odors delivered to the bee during the experiments.

\section{Behavior}

Behavioral experiments were carried out according to Felsenberg et al. (2011). In brief, during acquisition, one conditioning trial (CS-US pairing) lasted 30 sec: 10 sec before odor onset, an animal was placed into the experimental setup (placement). The CS (odor) was presented for $5 \mathrm{sec}$. Three seconds after the CS onset, the US (sucrose solution, $1.25 \mathrm{M}$ ) was applied to the antennae with a wooden toothpick. After extension of the proboscis, animals were allowed to lick the sucrose. US presentation to antennae and proboscis lasted $4 \mathrm{sec}$. For the remaining $13 \mathrm{sec}$, the animal was left undisturbed in the experimental setup.

During extinction, one extinction trial consisted of a 10-sec placement and a CS-only presentation for $5 \mathrm{sec}$. Afterward, the animal remained in the experimental setup for another 15 sec. Extinction took place with an intertrial interval of $10 \mathrm{~min}$.

One US-only trial consisted of a 13-sec placement and a presentation of the US-alone to the antennae of an animal. After extension of the proboscis, the animal was allowed to lick the sucrose solution. US presentation to antennae and proboscis lasted $4 \mathrm{sec}$. After $13 \mathrm{sec}$, the animals were taken out of the experimental setup.

During the final retention test, the CS alone was presented for $5 \mathrm{sec}$ after $10 \mathrm{sec}$ of placement.

Extension of the proboscis (PER) during placement or to the $\mathrm{CS}$ was noted. To be included in the analysis, animals had to show the unconditioned PER to all sucrose stimulations during the experiment and in a final test at the end of the experiment.

\section{Light as a context}

To test context dependency with lights, two LED spots (LED

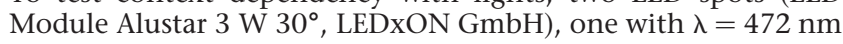
and one with $\lambda=597 \mathrm{~nm}$, were fixed $25 \mathrm{~cm}$ above the bee in the experimental setup. To characterize the lights, normalized irradiance curves measured with a fiber optic spectrometer (USB2000, Ocean Optics, Inc.) were plotted (Fig. 6).

The light was diffused with a translucent tracing paper fixed $5 \mathrm{~cm}$ above the bee (modified from Hori et al. 2006; Mota et al. 2011). To block most of the daylight coming through the windows, the whole setup was covered.

\section{Data analysis}

In order to determine significant within-session extinction, the McNemar test (STATISTICA 8, StatSoft Inc.) was used comparing the first with the last extinction trial. Difference over three extinc-

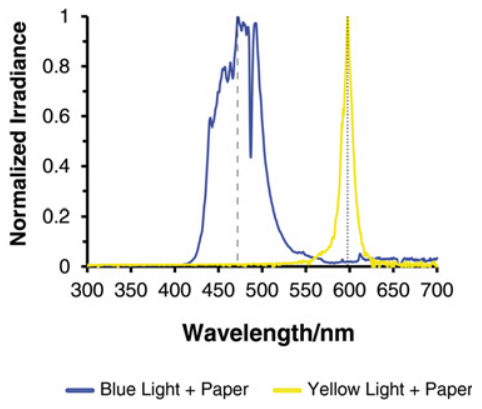

Figure 6. Normalized irradiance levels of blue and yellow lights. The maximum irradiance level measured behind translucent paper was detected at $472 \mathrm{~nm}$ for blue light (dashed line) and at $597 \mathrm{~nm}$ for yellow light (dotted line).

tion trials in blue vs. yellow illumination was tested with a repeated-measurement ANOVA, which can be used for dichotomous data under certain conditions and which has been shown by Monte Carlo simulations (Lunney 1970). Statistical differences between the groups in the final memory test were analyzed by means of a G-test (log likelihood ratio for contingency tables) (Zar 1984), corrected with Bonferroni correction if applicable. The G-test was also used to test for differences between groups of animals that received the same experimental protocol but with different lights (blue or yellow) illuminating the experimental setup. The respective groups were pooled if no statistical difference $(P>0.05)$ could be observed.

\section{Acknowledgments}

This study was supported by grant 01GQ0941 to D.E. from the German Federal Ministry of Education and Research (BMBF) within the Bernstein Focus Neuronal Basis of Learning and by grant EI 512/2-1 to D.E. from the Deutsche Forschungsgemeinschaft (DFG) within the joint project FOR 1363 Biogenic amines in insects: coordination of physiological processes and behaviour. We thank Jaime Martinez for his help with the spectrometer.

\section{References}

Bitterman ME, Menzel R, Fietz A, Schafer S. 1983. Classical conditioning of proboscis extension in honeybees (Apis mellifera). J Comp Psychol 97: $107-119$.

Bouton ME. 1993. Context, time, and memory retrieval in the interference paradigms of Pavlovian learning. Psychol Bull 114: 80-99.

Bouton ME. 2004. Context and behavioral processes in extinction. Learn Mem 11: $485-494$.

Bouton ME, Bolles RC. 1979. Role of conditioned contextual stimuli in reinstatement of extinguished fear. J Exp Psychol-Anim Behav Process 5: $368-378$.

Bouton ME, Swartzentruber D. 1986. Analysis of the associative and occasion-setting properties of contexts participating in a Pavlovian discrimination. J Exp Psychol-Anim Behav Process 12: 333-350.

Bouton ME, Westbrook RF, Corcoran KA, Maren S. 2006. Contextual and temporal modulation of extinction: Behavioral and biological mechanisms. Biol Psychiatry 60: 352-360.

Carter K, Lukowiak K, Schenk JO, Sorg BA. 2006. Repeated cocaine effects on learning, memory and extinction in the pond snail Lymnaea stagnalis. J Exp Biol 209: 4273-4282.

Castellucci V, Pinsker H, Kupfermann I, Kandel ER. 1970. Neuronal mechanisms of habituation and dishabituation of the gill-withdrawal reflex in aplysia. Science 167: 1745-1748.

Duka T, Crombag HS, Stephens DN. 2011. Experimental medicine in drug addiction: Towards behavioral, cognitive and neurobiological biomarkers. J Psychopharmacol 25: 1235-1255.

Eisenhardt D. 2012. Extinction learning in honey bees. In Honeybee neurobiology and behaviour (ed. CG Galizia, et al.), pp. 423-438. Springer, Heidelberg, London, New York.

Felsenberg J, Gehring KB, Antemann V, Eisenhardt D. 2011. Behavioural pharmacology in classical conditioning of the proboscis extension response in honeybees (Apis mellifera). J Vis Exp. doi: 10.3791/2282. 
Giurfa M, Sandoz JC. 2012. Invertebrate learning and memory: Fifty years of olfactory conditioning of the proboscis extension response in honeybees. Learn Mem 19: 54-66.

Graham BM, Milad MR. 2011. The study of fear extinction: Implications for anxiety disorders. Am J Psychiat 168: 1255-1265.

Greggers U, Menzel R. 1993. Memory dynamics and foraging strategies of honeybees. Behav Ecol Sociobiol 32: 17-29.

Greggers U, Mauelshagen J. 1997. Matching behavior of honeybees in a multiple-choice situation: The differential effect of environmental stimuli on the choice process. Anim Learn Behav 25: 458-472.

Hepp Y, Perez-Cuesta LM, Maldonado H, Pedreira ME. 2010. Extinction memory in the crab Chasmagnathus: Recovery protocols and effects of multi-trial extinction training. Anim Cogn 13: 391-403.

Holmes A, Quirk GJ. 2010. Pharmacological facilitation of fear extinction and the search for adjunct treatments for anxiety disorders-the case of yohimbine. Trends Pharmacol Sci 31: 2-7.

Hori S, Takeuchi H, Arikawa K, Kinoshita M, Ichikawa N, Sasaki M, Kubo T. 2006. Associative visual learning, color discrimination, and chromatic adaptation in the harnessed honeybee Apis mellifera L. J Comp Physiol A -Neuroethol Sens Neural Behav Physiol 192: 691-700.

Hori S, Takeuchi H, Kubo T. 2007. Associative learning and discrimination of motion cues in the harnessed honeybee Apis mellifera L. J Comp Physiol A -Neuroethol Sens Neural Behav Physiol 193: 825-833.

Kaplan GB, Heinrichs SC, Carey RJ. 2011. Treatment of addiction and anxiety using extinction approaches: Neural mechanisms and their treatment implications. Pharmacol Biochem Behav 97: 619-625.

Kuwabara M. 1957. Bildung des bedingten Reflexes von Pavlovs Typus bei der Honigbiene, Apis mellifica. J Fac Sci Hokkaido Univ Ser VI Zool 13: $458-464$.

Lagasse F, Devaud JM, Mery F. 2009. A switch from cycloheximide-resistant consolidated memory to cycloheximide-sensitive reconsolidation and extinction in Drosophila. J Neurosci 29: 2225-2230.

Lunney GH. 1970. Using analysis of variance with a dichotomous dependent variable: An empirical study. J Educat Meas 7: 263-269.

Merlo E, Romano A. 2008. Memory extinction entails the inhibition of the transcription factor NF-к B. PLoS One 3. doi: 10.1371 journal.pone.0003687.

Mota T, Giurfa M, Sandoz JC. 2011. Color modulates olfactory learning in honeybees by an occasion-setting mechanism. Learn Mem 18: $144-155$.

Myers KM, Davis M. 2002. Behavioral and neural analysis of extinction. Neuron 36: 567-584

Nathaniel TI, Panksepp J, Huber R. 2009. Drug-seeking behavior in an invertebrate system: Evidence of morphine-induced reward, extinction and reinstatement in crayfish. Behav Brain Res 197: 331-338.

Niggebrügge C, Leboulle G, Menzel R, Komischke B, de Ibarra NH. 2009. Fast learning but coarse discrimination of colours in restrained honeybees. J Exp Biol 212: 1344-1350.
Pauers MJ, Kuchenbecker JA, Neitz M, Neitz J. 2012. Changes in the colour of light cue circadian activity. Anim Behav 83: 1143-1151.

Peters J, Kalivas PW, Quirk GJ. 2009. Extinction circuits for fear and addiction overlap in prefrontal cortex. Learn Mem 16: 279-288.

Qin H, Dubnau J. 2010. Genetic disruptions of Drosophila Pavlovian learning leave extinction learning intact. Genes Brain Behav 9: 203-212.

Quirk GJ, Pare D, Richardson R, Herry C, Monfils MH, Schiller D, Vicentic A. 2010. Erasing fear memories with extinction training. J Neurosci 30: 14993-14997.

Rescorla RA. 1979. Conditioned inhibition and extinction. In Mechanisms of learning and motivation: A memorial volume to Jerzy Konorski (ed. A Dickinson), pp. 83-110. Erlbaum, Hillsdale, NJ.

Rescorla RA, Cunningham CL. 1977. The erasure of reinstated fear. Anim Learn Behav 5: 386-394.

Sandoz JC, Pham-Delegue MH. 2004. Spontaneous recovery after extinction of the conditioned proboscis extension response in the honeybee. Learn Mem 11: 586-597.

Sangha S, McComb C, Scheibenstock A, Johannes C, Lukowiak K. 2002. The effects of continuous versus partial reinforcement schedules on associative learning, memory and extinction in Lymnaea stagnalis. J Exp Biol 205: 1171-1178.

Sangha S, Scheibenstock A, Morrow R, Lukowiak K. 2003. Extinction requires new RNA and protein synthesis and the soma of the cell right pedal dorsal 1 in Lymnaea stagnalis. J Neurosci 23: 9842-9851.

Schiller D, Cain CK, Curley NG, Schwartz JS, Stern SA, LeDoux JE, Phelps EA. 2008. Evidence for recovery of fear following immediate extinction in rats and humans. Learn Mem 15: 394-402.

Stollhoff N, Eisenhardt D. 2009. Consolidation of an extinction memory depends on the unconditioned stimulus magnitude previously experienced during training. J Neurosci 29: 9644-9650.

Stollhoff N, Menzel R, Eisenhardt D. 2005. Spontaneous recovery from extinction depends on the reconsolidation of the acquisition memory in an appetitive learning paradigm in the honeybee (Apis mellifera). $J$ Neurosci 25: 4485-4492.

Takeda K. 1961. Classical conditioned responses in the honey bee. J Insect Physiol 6: 168-179.

Thompson RF, Spencer WA. 1966. Habituation: A model phenomenon for study of neuronal substrates of behaviour. Psychol Rev 73: 16-43.

Tomsic D, Pedreira ME, Romano A, Hermitte G, Maldonado H. 1998. Context-US association as a determinant of long-term habituation in the crab Chasmagnathus. Anim Learn Behav 26: 196-209.

Westbrook FR, Iordanova M, McNally G, Richardson R, Harris JA. 2002. Reinstatement of fear to an extinguished conditioned stimulus: Two roles for context. J Exp Psychol-Anim Behav Process 28: 97-110.

Zar JH. 1984. Biostatistical analysis. Prentice-Hall, Englewood Cliffs, NJ.

Received April 26, 2012; accepted in revised form August 7, 2012. 


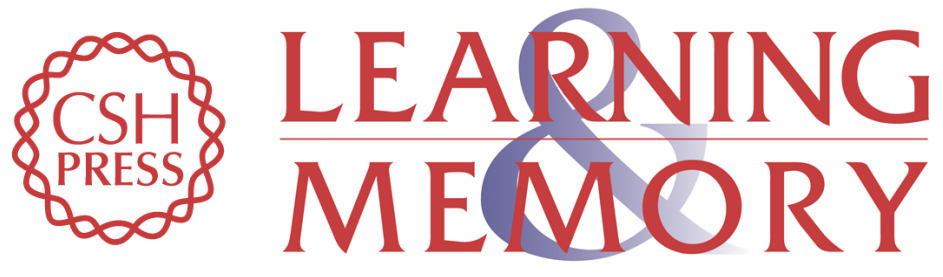

\section{Reinstatement in honeybees is context-dependent}

Jenny Aino Plath, Johannes Felsenberg and Dorothea Eisenhardt

Learn. Mem. 2012, 19:

Access the most recent version at doi:10.1101//m.026831.112

References This article cites 42 articles, 15 of which can be accessed free at: http://learnmem.cshlp.org/content/19/11/543.full.html\#ref-list-1

License

Email Alerting Receive free email alerts when new articles cite this article - sign up in the box at the Service top right corner of the article or click here. 